\title{
PROJETO VIDA ATIVA: UMA PRÁTICA CULTURAL DESENVOLVIDA NA UNIVERSIDADE ESTADUAL DO SUDOESTE DA BAHIA
}

\author{
Virginia Maria Mendes Oliveira Coronago ${ }^{1}$
}

\section{RESUMO}

Este relato de experiência objetiva elaborar uma narrativa sobre o Projeto Vida Ativa. Parte de um levantamento sobre o envelhecimento populacional, principalmente no que se refere à realidade brasileira, e procura elaborar um roteiro que abarque alguns enfrentamentos resultantes do fenômeno do Envelhecimento no Brasil até a construção de uma proposta em prol de uma velhice com melhor qualidade.

Palavras-chave: Música. Envelhecimento. Educação. Qualidade de vida.

\begin{abstract}
This experience report aims to draw up a narrative about Project Active Life. Part of a survey on the aging population, especially in relation to the Brazilian reality, and seeks to develop a roadmap that encompasses some confrontations resulting from the phenomenon of aging in Brazil until the construction of a proposal towards an old age with better quality.
\end{abstract}

Keywords: Music. Aging. Education. Quality of life.

\footnotetext{
${ }^{1}$ Mestre e doutoranda em Ciências Sociais, ocupa o cargo de Analista Universitário da UESB e é membro do Grupo de Estudos e Pesquisas sobre Envelhecimento. E-mail: virginiacoronago@, hotmail.com
}

\begin{tabular}{l|l|l|l|l}
\hline Revista Extensão \& Cidadania & Vitória da Conquista & v. 1, n. 2 & p. 147-154 & jul/dez. 2013 \\
\hline
\end{tabular}


O aumento da longevidade na população brasileira é um dado revelado, ano após ano, nas pesquisas do Instituto Brasileiro de Geografia e Estatística (IBGE). Confirmamos esta tendência quando comparamos o número de brasileiros acima de 60 anos com o número de crianças com menos de 5 anos. Em 1981, para cada idoso havia duas crianças na faixa de idade acima citada. A partir de 2002 os dados se inverteram e, atualmente, o Brasil conta com 120 idosos para cada 100 crianças.

Segundo dados da Pesquisa Nacional por Amostra de Domicílios (PNAD), o crescimento no número de idosos é o triplo do da população como um todo. A participação das pessoas com 25 anos ou mais de idade no total da população brasileira vem aumentando a cada ano, especialmente entre 2004 (53,7\%) e 2009 (58,4\%), enquanto a das pessoas na faixa etária até 24 anos de idade vem diminuindo, de $46,3 \%$ para 41,6\% no mesmo período. Na comparação entre 2008 e 2009, houve redução de 642 mil pessoas na população até 24 anos de idade, enquanto a faixa etária de 25 a 59 anos aumentou em 1,8 milhão de pessoas. A taxa de fecundidade foi de 1,9 filhos por mulher em 2008 e 2009, contra 2,1 em 2004.

$\mathrm{Na}$ população com 60 anos ou mais, o crescimento foi de 697 mil pessoas entre 2008 e 2009, o que representou um aumento de $3,3 \%$, contra uma elevação de $1 \%$ no total da população residente no país. Em 2009, 11,3\% dos brasileiros tinham 60 anos ou mais de idade, à frente dos 11,1\% em 2008 e dos 9,7\% em 2004. A região Norte seguiu com a maior concentração relativa aos grupos etários mais jovens, sobretudo de pessoas de 5 a 14 anos de idade, 21,4\% em 2009. Já as regiões Sul e Sudeste apresentaram os maiores percentuais na faixa de 40 a 59 anos $(25,6 \%$ e $26,2 \%)$ e na faixa de 60 anos ou mais (12,7\% e $12,3 \%$ ). 
Gráfico 1 - Evolução da proporção das faixas etárias

da população brasileira. Brasil, 2010-2050

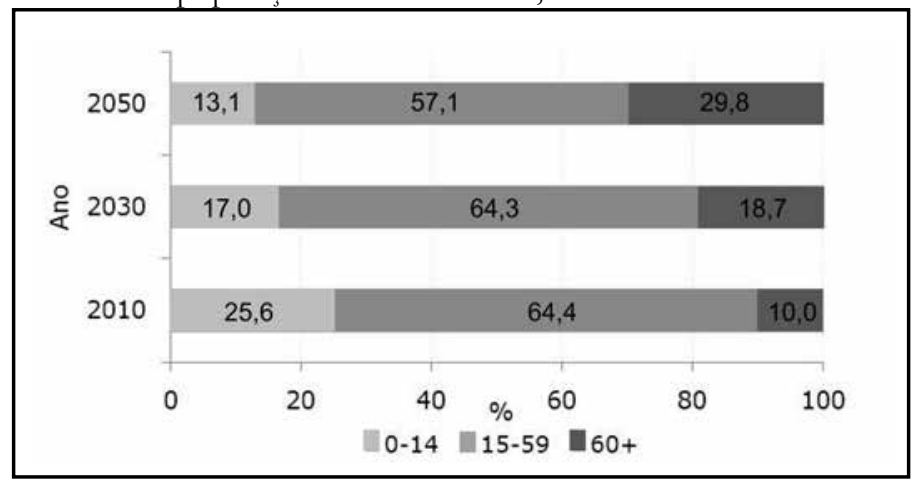

Fonte: IBGE, 2010. [quando for diagramar, retirar a borda preta, o título do interior do gráfico e a fonte]

O notável crescimento do número de idosos na população geral reflete ganhos positivos em termos de desenvolvimento social, contudo, o processo de envelhecimento humano também representa muitos desafios, face às demandas emergentes e à falta de provimento de serviços e programas alternativos de apoio a esse grupo. As ações existentes, nas áreas humanas e sociais, estão muito aquém em quantidade e eficácia se comparadas às áreas de necessidade vital e que não estejam voltadas para a pessoa idosa.

Desse modo, há que se pensar em estratégias para atender as lacunas existentes, por intermédio de uma cultura investigativa, dinâmica, centrada em uma visão estratégica com vistas ao futuro, e com avanços e ganhos políticos e sociais, pautada na qualidade, volume e rapidez de resolutividade.

Visto que a qualidade de vida na velhice tem como características primordiais a promoção da autonomia e da independência do idoso, então, desenvolver, adaptar e testar ações educativas para a manutenção e/ou recuperação da autonomia e independência nas atividades da vida diária, além de promover a reinserção social destes, é o nosso maior desafio. 
Sabe-se que os fatores psicológicos adquiridos culturalmente têm uma grande influência no modo como as pessoas envelhecem. A autoeficiência (a crença na capacidade de exercer controle sobre sua própria vida) está relacionada às escolhas pessoais no que se refere ao comportamento durante o processo de envelhecimento. Saber superar adversidades determina o nível de adaptação às mudanças advindas do processo natural e diversificado de envelhecimento. A capacidade de adaptação frente às mudanças faz parte do ser humano - "Jovens" e "velhos" não são diferentes quanto à capacidade de solucionar problemas.

Diversas concepções reforçam a percepção das limitações, das perdas, das incapacidades e das doenças como aspectos salientes das representações da velhice. Contudo, a perspectiva Gerontológica Social e várias outras áreas que estudam a condição humana propõem alguns modelos teóricos multidimensionais que analisam a relação entre as perdas e os ganhos. Os modelos expõem que, apesar do envelhecimento continuar sendo representado na base de perdas, os idosos possuem muita capacidade reserva, ainda inexplorada, quer dizer, ganhos que passam despercebidos e, em consequência, não são valorizados. Citase, aqui, o "modelo de envelhecimento bem sucedido", assinalado por Baltes, P. B. e Baltes, M. M. (1990, p. 4):

[...] o envelhecimento bem sucedido precisa de uma avaliação sustentada em uma perspectiva multidimensional, na qual fatores objetivos e subjetivos sejam considerados dentro de um contexto cultural, que contém demandas específicas.

Segundo Chauí (1979), ser velho, em nossa sociedade, é lutar para continuar sendo homem. Para a autora, a opressão na velhice se realiza de múltiplas maneiras, "algumas tacitamente brutas, outras tacitamente permitidas". Ela complementa, ainda, que a opressão do velho acontece por intermédio de mecanismos institucionais, a exemplo do processo burocrático de aposentadoria, por abusos, violências psicológicas, muitas vezes evidenciadas, outras vezes sutilmente e quase invisíveis. 
De acordo o artigo 230 da Constituição da República (1988), a família, a sociedade e o Estado têm o dever de amparar as pessoas idosas, assegurando sua participação na comunidade, defendendo sua dignidade e bem-estar e garantindo-lhes o direito à vida.

A Universidade Estadual do Sudoeste da Bahia (UESB) confere um significado especial à área de extensão, desenvolvendo ações que promovem uma participação ativa na construção e na coesão social, no aprofundamento da democracia, na luta contra a exclusão social e na defesa da diversidade cultural. A extensão na UESB envolve uma vasta área de prestação de serviços e seu público é variado: grupos sociais populares, movimentos sociais, comunidades locais/regionais, governos locais e o setor público/privado.

E, nesta perspectiva, no ano de 1999, a UESB suscitou um processo de discussão sobre a temática do envelhecimento com o início do "Universidade Aberta com a Terceira Idade" (UATI), no campus de Jequié - um projeto interdisciplinar, reconhecido e aprovado pelo Departamento de Saúde e pela Pró-Reitoria de Extensão da referida Universidade. Por meio de uma mobilização, o Projeto, sob a Coordenação Geral da Prof ${ }^{a}$ Ms. Edméia Campos Meira, teve início com oferecimento de diversas oficinas voltadas para o público idoso.

Entre as ações oferecidas estava a Oficina de Cantoterapia, sob a minha coordenação, que obteve bastante aceitação dos participantes, fixando um público de sessenta (60) pessoas. A oficina era desenvolvida numa sala de aula da Universidade. O grupo era assíduo e motivado. Além do trabalho desenvolvido em sala, aconteciam apresentações públicas em eventos da instituição, da comunidade em geral e em outras cidades. Essa experiência foi altamente motivadora e me despertou para os estudos sobre o processo de envelhecimento, quando me integrei ao Grupo de Estudos e Pesquisas sobre o Envelhecimento (GREPE). Algumas das ações desenvolvidas junto ao grupo foram apresentadas no I Congresso de Geriatria e Gerontologia do Mercosul, cujo tema era: "Cantando a vida na terceira idade". Este trabalho objetivava um redimensionamento das condições de vida do homem em processo 
de envelhecimento mediante exercício sociopolítico e cultural, com utilização das práticas musicais como exercício que promove a integração, o equilíbrio emocional e a ampliação dos conhecimentos e práticas culturais que valorizem a autoestima, na perspectiva de uma vida em plenitude.

No ano de 2005 resolvemos que seria interessante desenvolvermos essa proposta no Campus de Vitória da Conquista, assim, cadastramos o Projeto "Música, Linguagem da emoção" em parceria com o Projeto "Juventude Acumulada" que tinha como uma das ações a oficina de Cantoterapia. A oficina era realizada, a princípio, no Centro de Cultura Camilo de Jesus Lima, em Vitória da Conquista, após mudanças administrativas, fomos acolhidos pelo PROLER/UESB, apoiados pela Prof ${ }^{a}$ Heleusa Câmara. O espaço era limitado para o número de participantes e, desde março de 2007, o projeto concentra a maioria das ações no Centro de Extensão Comunitária da UESB. O público atendido é de cerca de 100 idosos ao ano, com atividades diversas: práticas de canto, apresentações públicas, pesquisas e registros de músicas populares e canções folclóricas, culminando em 2008 com a gravação de um CD; são desenvolvidos estudos sobre direitos humanos, divulgação de produções escritas realizadas pelos participantes, momentos de reflexões acerca da saúde com abordagens multidisciplinares, e recentemente abrimos espaços para pesquisa de grupos de alunos de escolas e universidades interessadas no tema. A partir destas experiências, fomos convidados a prestar uma assessoria em música junto ao Projeto Interinstitucional Tecnologias Assistivas Para Inclusão do Idoso Portador de Parkinson (TAIP) que foi desenvolvido em dois contextos: na Universidade Federal de Santa Cantarina (UFSC) e na Universidade Estadual do Sudoeste da Bahia (UESB), Campus de Jequié. O portador de DP e a sua família cuidadora participavam de atividades multiprofissionais por meio dos subprojetos: o Grupo de Ajuda Mútua (GAM), a Fisioterapia, a Educação Física e o Grupo de Vivências Musicais. Os resultados das Vivências Musicais foram publicados na Revista Brasileira de Geriatria e Gerontologia (http://revista.unati.uerj). 
Em 2010 ampliamos as ações e identificamos o trabalho como "Projeto Vida Ativa". Em 2011 firmamos uma parceira com o Conselho Municipal do Idoso e o Ministério Público para a realização do Projeto "Pessoa Idosa, Direitos e Cidadania". Desse modo, participamos de ações socioeducativas em bairros com maior índice de violação dos direitos da pessoa idosa. Como uma das ações do referido projeto, realizamos uma caminhada pela cidadania do Idoso. A caminhada contou com a presença dos idosos participantes do Grupo Vida Ativa, representantes do Conselho do Idoso, do Ministério Público, do Centro de Referência da Assistência Social, da Secretaria de Desenvolvimento Social e de alunos do Educandário Juvêncio Terra.

Compreendemos, assim, que mesmo com formas próximas e distantes na percepção do processo de envelhecimento, as teias tecidas entre o passado, o presente e as expectativas para o futuro se configuraram na busca de viver melhor, mediante participação em atividades que promovam o bem-estar e a reinserção social.

Sabemos da nossa responsabilidade em ampliar o debate sobre o tema, avaliando alternativas que possibilitem minimizar o impacto cultural, e propor a implementação de políticas públicas direcionadas à manutenção do bem-estar integral da população idosa. Fica, para nós, um trecho sublinhado por Morin (2005, p. 155): “Que significa viver para viver? Viver para gozar a plenitude da vida. Viver para realizar-se. A felicidade constitui, certamente, a plenitude da vida".

Nesta diversidade de interpretações, concluímos que cada um tem um olhar diferenciado para as coisas da vida, mas o que de fato move o homem e produz resultados é a busca contínua e interessada pelas respostas que se deseja obter.

\section{Referências}

BALTES, P. B.; BALTES, M.M. Success fulaging. Perspectives from the behavioral sciences. Cambridge: Cambridge University Press, 1990. 
BRASIL. Ministério da Saúde. Secretaria de Políticas de Saúde. Portaria n. 1.395, de 9 de dezembro de 1999. Brasília, 1999. Disponível em: < http:/ / dtr2004.saude.gov.br/susdeaz/legislacao/arquivo/Portaria_1395_ de_10_12_1999.pdf>. Acesso em: set. 2008.

CHAUÍ, Marilena. Apresentação. In: BOSI, E. Memória e sociedade. Lembranças de velhos. São Paulo: EDUSP, 1987. Disponível em: $<$ www.sbsociologia.com.br/portal/index.php?option=com $>$. Acesso em: ago. 2013.

INSTITUTO BRASILEIRO DE GEOGRAFIA E ESTATÍSTICA. Evolução da proporção das faixas etárias da população brasileira. Brasil, 20102050. Disponível em: <http://www.ibge.gov.br.>. Acesso em: abr. 2007.

MORIN, E. O Método 5: a humanidade da humanidade. 3. ed. Porto Alegre: Sulina, 2005.

ORGANIZAÇÃO MUNDIAL DA SAÚDE (OMS). Plano de Ação Internacional Sobre o Envelhecimento. Disponível em: <http://www.who. int/en/>. Acesso em: jan. 2009. 